\title{
More Than One Way to Float Your Boat : Product Use and Sustainability Impacts
}

\section{Martin, Diane M.}

2019-03

Martin , D M , Harju , A A , Salminen , E \& Koroschetz , B 2019 , ' More Than One Way to Float Your Boat : Product Use and Sustainability Impacts ', Journal of Macromarketing, vol. 39 , no. 1 , pp. $71-87$. https://doi.org/10.1177/0276146718817600

http://hdl.handle.net/10138/309230

https://doi.org/10.1177/0276146718817600

unspecified

acceptedVersion

Downloaded from Helda, University of Helsinki institutional repository.

This is an electronic reprint of the original article.

This reprint may differ from the original in pagination and typographic detail.

Please cite the original version. 


\title{
More Than One Way to Float Your Boat: Product Use and Sustainability Impacts
}

\author{
Abstract \\ Concern for sustainability crosses multiple areas of scholarly inquiry. At the macro level, \\ sustainability research has focused primarily on institutional actors and systemic change efforts. \\ At the consumer level, sustainability research has focused primarily on consumer product choice \\ and post-use disposal. Employing a practice theory lens, this study examines how consumer \\ practices during product use results in a wide variance in overall environmental sustainability \\ impacts. Emerging practice configurations illustrate the ways rules as meaning, at both the macro \\ level institutional regulations and micro level of cultural expectations shape consumer options. \\ Practice configurations also illuminate the ways material marketplace resources, both stagnated \\ products and innovations, provide opportunity for variance. Finally, the competence element of \\ practice varies between a traditional consumer culture ethos and new practices vis-a-vis \\ consumer resourcefulness. This study provides a contribution to the link between \\ macromarketing and consumer culture theory in the centrality of enforcement of both \\ governmental level regulations and consumer best practices for improved environmental \\ sustainability.
}

Key Words: Practice Theory, Sustainability, Product Use, Marine Anti-Fouling, Consumer Culture Theory 


\section{Introduction}

The overall environmental impact of consumer behavior is of major concern for the current and future wellbeing of life. In this paper we approach these concerns by investigating variations in product use and associated impacts on environmental sustainability. Traditionally, sustainable consumption research has mainly focused on product choice or product disposal schemes, such as reduce and recycle campaigns and practices (Benton 2015; Brosius, Fernandez, and Cherrier 2013; Lastovicka and Fernandez 2005). Other research has investigated the gap between consumers espoused attitudes and their buying behavior, moralizing for green consumption, and promoting sharing and anti-consumption as means of restricting the negative effects of overconsumption (McDonagh and Prothero 2014). Action research efforts to change consumer behavior range from limiting over-consumption, improved decision-making processes, and consumer-led anti-consumption movements (e.g., Cherrier 2010; Kozinets and Handelman 2004; Vermeir and Verbeke 2006). Taken together, the majority of sustainable consumption research has focused largely on two ends of the product consumption life-cycle, the product acquisition, such as buying green products (e.g., Gupta and Ogden 2009; Moisander 2007; Vermeir and Verbeke 2006; Young et al. 2010), or product disposal, such as recycling (Bulkeley and Gregson 2009; Ekström 2014). Theorizing consumer product use sustainability affects (Prothero et al. 2011) remains under-developed.

Natural science studies provide some information of environmental impacts of product use. This impact is often measured through Life Cycle Analysis (LCA), "a tool [used] to assess the environmental impacts of product systems and services, accounting for the emissions and 
resource uses during the production, distribution, use, and disposal of a product" (ISO.14040, 1997). The traditional LCA input-output analysis thus provides some limited information for understanding product use and variance of overall environmental impact, by focusing for example on the "energy and detergent consumption during the use of a washing machine, or the environmental load associated with the disposal of mobile phones" (Hertwich 2005, p. 4673). However, Hertwich (2005, p. 4673) also notes that while "the LCA has proven useful in the context of sustainable production [it] has been little used in the sustainable consumption." From a natural science perspective theorizing the ways product use relates to the overall sustainability, and how it affects the full consumption cycle, also remains underdeveloped.

This paper is a part of a multidisciplinary project undertaken by consumer theorists, marine scientists, and legal scholars who together examine the use of anti-fouling (AF) paint in boat maintenance practices among Finnish, Swedish, German leisure boaters in the Baltic Sea. Antifouling paints are designed to harmful to barnacles and algae, providing much needed toxins to help boaters keep their hulls clean. The boat hull is the primary part of the boat that interacts with the sea where AF paints cause high levels of toxins in the catchment and the sea (Eklund and Eklund 2014; Karlsson and Eklund 2004). Copper and zinc in particular are useful toxins, however the over-use of AF paints prove harmful to benign marine animals. This study examines boaters' anti-fouling practices, by which we mean the practice configuration composed of scraping and washing the boat hull and repainting. We also examine the disposal of paint flakes generated during scraping as part of the antifouling practice. Our focus on the use of AF painting of boat hulls offers the opportunity to uncover and examine variance of sustainable impacts in consumer product use. 
While the overarching definition of sustainability accounts for environmental, economic and social sustainability (Heiskanen and Pantzar 1997; Kilbourne, McDonagh, and Prothero 1997; Martin and Schouten 2012), it leaves out a closer examination of what constitutes the practices of product use and, importantly, how the different practice elements shape the overall sustainability of product use. Our work thereby addresses calls (e.g., Brosius, Fernandez, and Cherrier 2013; Sahakian 2010; Prothero et al. 2011) for policy makers and marketing researchers to view consumption as full consumption cycle of acquisition, consumption and disposal. Adopting a practice theory lens (e.g., Shove, Pantzar, and Watson 2012) to examine sustainable consumption and the environmental impacts of product use fills a gap in the sustainable consumption literature (Prothero et al. 2011).

We adopt a consumption as practice lens which allows us to examine the use of products and the different roles material, competency and meaning play in practice configurations (Shove 2017). Practice theory allows us to distinguish between different yet equally important elements that together form the practice, and thus to analyze the significance of each dimension in relation to sustainability of the product use. As practice theory is not a unified theory (Nicolini 2017a; Reckwitz 2017; Schatzki 2001) we draw in particular on the relationships between material, meaning and competence (Shove, Pantzar, and Watson 2012) as elements that make up a practice. A practice theory lens allows examination of practice configurations as a whole without demanding separation between micro and macro levels. In this paper we examine the duality of micro-macro divisions in particular with respect to macro and micro interventions of practice configuration components which increase product use sustainability. We link consumer culture perspectives to macro-level themes of the ways different practice configurations either contribute to or detract from sustainable consumption. In doing so we hope to provide an increased 
understanding of the significance variation in practice configurations of sustainability in the context of product use. This line of enquiry allows us to examine the various configurations of maintenance practice and how variation in practice elements influence sustainability outcomes. After pinpointing different configurations of practice elements, we posit four practices configurations of the leisure boaters: The Proper Boater, the Opportunist, the Green Boater, and the Negotiator.

\section{Literature Review}

\section{Sustainable Consumption and Product Use}

Marketing has a well-earned reputation for driving over-consumption and consequentially environmental degradation, income inequity and humanitarian crises; yet, these consequences are also foundational to an interest in sustainable consumption research (Cohen 2006), evidenced by recent special issues (see e.g., McDonagh and Prothero 2014 for a review), including the Journal of Macromarketing $(2010,2014)$ and the Journal of Marketing Management $(1998,2012,2015)$. This research encapsulates a variety of philosophical perspectives pertaining to consumer attitudes, product acquisition and product disposal behaviors. The missive at the core of this work is sustainable development, commonly defined as meeting "the needs of the present without compromising the ability of future generations to meet their own needs" (World Commission on Environment and Development 1987, p. 8). Marketing scholars adapted this definition with a focus on consumption (Dolan 2002; Heiskanen and Pantzar 1997; Shrivastava 1995), taking into account the environmental, economic and social sustainability as applied to 
marketing writ large (Heiskanen and Pantzar 1997; Kilbourne, McDonagh, and Prothero 1997; Martin and Schouten 2012).

Consumer ethics and morality frame much of the thinking about consumers and sustainability. Indeed, early typologies linking sustainability and consumers (Fisk 1974) admonished consumers to consider the environmental costs of consumption. Webster (1975), for example, defined a "socially conscious consumer" (p.188) as one who considers the public consequences of individual consumption, using consumption to affect social change. Subsequently, scholars have conceptualized the "critical consumer" (p. 219) as one endowed with the capacity for and interest in social and political change in the form of purchasing power (Sassatelli, 2006, 2008) and informed decisions. The "morally enlightened agent" (p. 841), Giesler and Veresiu (2014) argue, solves the sustainability problem by drawing on expert knowledge and transformation to a "new moralized self-understanding" (p. 841).

However, others including Devinney, Auger, and Eckhardt (2010) and Bertilsson (2015), have questioned the veracity of the ethical consumer ethos. Chatzidakis, Maclaran, and Bradshaw (2017) challenge this view and look instead beyond the individual, arguing that a macro view of consumption brings consumer resistance to neo-liberal capitalism and the associated politics and environmental ethics into focus. They examine collective action in a particular space and place, "exploring the relationship of (ethical and green) consumption activities with space/place and a broader nexus of politics" (p. 496). Yngfalk (2016) also explores the ways in which the neo-liberal discourses of consumerism and consumer choice in fact place responsibility on the consumer for ethical decision-making. Additional macro level research investigates sustainability from structural and institutional perspectives, including market initiatives, such as third-party labeling schemes (Thøgersen 2005), changes in the 
dominant social paradigm (Prothero et al. 2011), and changes in market level ideologies (Holt 2012).

Sustainability often is examined as embedded in either the product or consumer choice (Assadourian 2010; Gupta and Ogden 2009; Moisander 2007; Vermeir and Verbeke 2006; Young et al. 2010). While marketers have traditionally been interested in how to get consumers to buy more, other sustainable consumption research has directed attention towards encouraging consumers to consume less, or to consumer better (Jackson 2009). In terms of the consumption life-cycle, sustainability research tends to focus on the end points of the product life-cycle. Product acquisition has long been at the center of research on sustainable consumption. Yet even consumers who propone to hold positive attitudes regarding sustainability nevertheless fail to choose the more sustainable products available. Researchers have long been unsuccessful in explaining this behavior-attitude gap (Vermeir and Verbeke 2006), where even environmentallyminded consumers do not make purchases accordingly (Gupta and Ogden 2009; Vermeir and Verbeke 2006). This disconnect may partly stem from the attitude-behavior studies themselves which tend to examine behavioral items in isolation (Shove 2010a) rather than through comprehensive interrelated elements. Here practice theory proves useful as a tool for analysis. Indeed, Hand, Shove, and Southerton (2005) argue that "rather than analyzing (sic) moments of acquisition, or the cultural significance of the specific objects and technologies, [to] focus on the processes and practicalities of their use" (p. 2) is crucial. Addressing these concerns OzdamarErtekin and Atik (2015) for example, examined how fashion-minded consumers, who find it difficult to shop their values in a social system where fast fashion is the norm, seek out providers offering "slow fashion" as a visible signal of consumer sustainability values. 
Research has also investigated the other end of product life, disposal. As early as the 1970's Jacoby, Berning, and Dietvorst (1977) argued that more attention should be paid to product disposal. More recent studies have addressed disposal, including not only waste management but product recycling and upcycling (e.g., Benton 2015; Brosius, Fernandez, and Cherrier 2013; Kalverkamb and Raabe 2018; Lastovicka and Fernandez 2005; Närvänen, Mesiranta, and Hukkanen 2013; Price, Arnould, and Curasi 2000).

\section{Practice Theory Approaches and Sustainable Consumption}

The first generation of practice theories (Bourdieu 1977; Giddens 1984) focused on human actors. Subsequent practice theories extended this focus to include non-human entities as essential for the production of social practices (Gherardi 2017; Preda 1999; Orlikowski 2007; Schatzki 2002). By shifting the focus from the individual to common social processes (Warde 2014), practice theory developed into a non-individualistic perspective on consumption (e.g., Hargreaves 2011; Nicolini 2017b) useful for analyzing consumer behavior (Welch and Warde 2017).

Schatzki (2002), argues that the nexus of practices is where social action as organized activity both transpires in and is understood in context. Shove, Pantzar, and Watson (2012) extend Schatzki (2002) and further develop the material dimension of practice theory, classifying practice elements as material, competence and meaning. Because changes in one element lead to changes in the other elements, the ways material, meaning and competence configure in consumption practice configurations allows for transformational potential regarding sustainable consumption (Magaudda 2011; Shove, Pantzar, and Watson 2012). 
We adopt the practice-theoretical approach developed by Shove, Pantzar, and Watson (2012) as it allows for a detailed examination of the painting practice in leisure boat maintenance. The material aspect encompasses objects and tools (e.g., paints, brushes, tarps, boats) and infrastructures (e.g., recycling facilities for used paint tins, washing facilities) (Hand, Shove, and Southerton 2005). Agency of materiality emphasizes the importance of objects in shaping or being shaped by practices. The practice element of competence refers to a bundle of practical knowledge, skills, technique, and forms of understanding. In boat maintenance, these understandings include traditional maintenance practices, and also the skills required to carry out the practice of painting. The third practice element, meaning, refers to symbolic meanings and aspirations, to "the social and symbolic significance of participation at any one moment" (Shove, Pantzar, and Watson 2012, p. 23), and links to tradition and history. Practices exist though the linkage of all three elements: the body engaged in painting, the boat being painted, the paint itself with associated tools, regulations governing the paint and its use and disposal, and the technique of applying the paint. Although not equated with meaning per se, general understandings, what Schatzki $(2001,2002)$ calls "culturally significant understandings" show up as "culture in practice" (Welch and Warde 2017). This linkage between general understandings and culture helps us see the culturally varied configurations of practice, informed by and embedded in the larger socio-cultural systems of meaning and historicity.

It is not surprising that practice theory has been increasingly used in the sustainable consumption studies (e.g., Hand, Shove, and Southerton 2005; Røpke 2009; Hargreaves 2011; Sahakian and Wilhite 2013; Welch and Warde 2015; Casey, Lichrou, and O'Malley 2017). This is in part because of a holistic focus on consumption (Røpke 2009) but also due to its relevance to the materiality of environmental problems (Sahakian and Wilhite 2013). Practice theory thus 
offers a way out of the attitude-behavior and value-action gap conundrum (Welch and Warde 2015) through an analysis of sustainable consumption patterns within embedded social practices (Warde 2005; Røpke 2009; Shove 2010b). Changing practice elements offers intervention opportunities for public policy efforts toward more sustainable outcomes.

Because practices occur as arrangements (Schatzki 2002), as bundles of different practices that span spatial and temporal domains (Shove 2017), the distinction between micro and macro does not present as a useful division (Nicolini 2017a, 2017b). Instead, practices need to be examined from a perspective that considers the influence of both cultural and material dimensions (Gherardi 2017; Reckwitz 2017). By examining product use through a practicetheoretical lens we aim to increase the understanding of the importance of the various interlinked dimensions in practice configurations regarding sustainability impacts of the full product life cycle. We draw attention to the environmental effect of different configurations, and how these either contribute to or detract from sustainable consumption.

\section{Methodology}

\section{Context}

Maintenance of more than 3.5 million boats on the Baltic Sea adds significantly to the poor condition of one of the Earth's most polluted seas (Eklund and Eklund 2014). Hull AF practices are particularly implicated in environmental sustainability as the hull interacts directly with the marine environment while in the water, and affects the catchment during maintenance and storage. In this study we focus in particular on the anti-fouling hull maintenance practice. By this 
we mean the practice configuration composed of scraping, applying new paint and disposing of the old paint flakes on the ground and as they pollute the catchment through runoff. Most leisure boat owners use toxic AF paint to keep barnacles from attaching to the hull, thereby improving maneuverability and decreasing drag, which in turn lessens fuel consumption costs. AF paints cause particular problems as their use adds to the distribution of biocides in the coastal ecosystem (Thomas and Brooks 2010), leading to unintended deaths of benign marine organisms. Since most boats are stored in boatyards located adjacent to the sea, loose paint fragments from the scraping and washing process pollute the soil and are washed into the sea (Eklund and Eklund 2014; Eklund, Johansson, and Ytreberg 2014). These practices are particularly harmful in the semi-enclosed Baltic Sea (Ytreberg, Karlsson, and Eklund 2010).

\section{Data Collection and Analysis}

We combined various qualitative data collection methods, including ethnographic interviews, photographic and video data collection and participant observation. Ethnography has been used to study everyday cultural consumption (Arnould and Wallendorf 1994; Arnould and Thompson 2005), consumer practices in the context of environmental behavioral change (Hargreaves 2011) and sustainable consumption (Casey, Lichrou, and O'Malley 2017). It enables researchers to go beyond superficial or socially desirable meanings (Goulding 2005) and aids understanding of culturally shaped actions and everyday social interactions (Arnould and Wallendorf 1994). Participant observation allowed us to study the relationships among people, practice configurations, and different patterns in sociocultural contexts (Jorgensen 1989). 
Since environmental issues are not constrained within national boundaries, a multinational, multi-sited strategy for data collection proved to be useful. Ethnographic data were collected in five different boat yards around the Baltic Sea, in Germany (Kiel), Sweden (Gothenburg) and Finland (Helsinki). These countries and sites were chosen in part due to the salinity of the sea at their shores; Sweden also boarders the Atlantic Ocean. These sites offered a wide variety of marina contexts in terms of infrastructures, management and size. During spring boat maintenance seasons, we observed and interacted informally with boaters preparing their boats for summertime use. We conducted over 30 interviews with boat owners to learn how boat maintenance practices are organized in terms of material, meaning and competence. The majority of interviews with boaters lasted between 30 and 90 minutes and took place either in the boatyards or in nearby cafés. We also interviewed boaters at the annual boat fairs in 2015 and 2016 in Helsinki and Stockholm. We conducted two interviews with marina harbormasters responsible for daily operations. Over the course of the project we provided periodic presentations to competent authorities (toxic material expert representatives to the UE from each of the three countries). In their capacity as experts for public policy, they walk a fine line between industry needs and environmental needs and thus declined to participate as informants in the project. All interviews were recorded, and transcribed resulting in over 500 pages data. Data were analyzed by native language speakers.

We generated 10 pages of field notes from the observations. These observations provided insights of different marina infrastructure designs, including dedicated areas for hull washing and waste management systems. Sixty photographs document distinct features of each marina. Boating blogs, boat magazines, AF paint regulations and policy documents were also collected. 
Applying practice theory framework to analysis of qualitative data allowed us to examine materiality, competence and meaning from the perspective of boat owners. Our data analysis focused on emic data, and the importance of observation and interviews to discern practice elements in situ. Maintaining our focus on AF practices, we started by mapping the different practice elements of meaning, doing and material to get an overall picture of the practices (Shove, Pantzar, and Watson 2012). A review of Nordic boat maintenance regulations combined with our interview and observation data enabled us to understand how AF practices are perceived and enacted among boaters. We started analyzing the data through open coding and coupled the analysis with the fieldwork findings, while adhering to the recommended iterative process ongoing throughout the research project (Belk, Fischer, and Kozinets 2012). Employing a hermeneutical analysis (Spiggle 1994) we were able to develop a sense of the whole (Arnold and Fischer 1994). We then returned to the policy documents and natural science reports to compare boat owners' perception of sustainability with the environmental research findings. Our focus remained on the environmental effects of AF paint, meaning other boat maintenance practices, such as engine repair, deck and cabin maintenance and instrument renewal were intentionally left out of our analysis.

-INSERT TABLE ONE HERE-

\section{Findings}

Institutional Actors: Regulations and Market Resources 
We initiate the macro level analysis of sustainability issues related to the Baltic Sea antifouling practice with an examination of regulatory and market resources. European Union and national regulations, and market resources are macro level institutional actors in sustainable boat maintenance practices. The 1989 European Biocidal Products Regulation (BPR 1989) identified the biocides allowed for use in antifouling paints, banning the most toxic of these compounds, tributyltin (TBT), but leaving other toxins, copper and zinc, under regulated. Copper is not harmful per se as it is naturally found in the marine environment and for many species it is a necessary component for growth or metamorphosis (Lewis and Cave 1982). Indeed, copper is only harmful if it exceeds the tolerance level of for the specific organism (Cao et al. 2005). However, marine biologists have examined the effects of copper on marine organisms and discovered that $\mathrm{Cu}$-ions (copper) in the sea are problematic to crustaceans and fish at very low level as they interfere with their olfactory sense and for that reason they have difficulties finding nourishment, which leads to an increase of death of these creatures (Baldwin et al. 2003). The release rates of hazardous substances leaching from AF paints on the Swedish and German Baltic coasts where found to offer greater adherence to more sustainable maintenance and have significantly lower rates of copper than Finnish marine environments where traditional AF paints are regularly used (Eklund et al. 2016). Multidisciplinary attempts to review EU regulations for more stringent oversight of copper-zinc toxicity levels and chemical interactions are ongoing (BONUS Change, 2014).

Paints are designed to slowly leach toxic chemicals into the sea, killing barnacles and algae that attempt to attach to boat hulls (Karlsson and Eklund 2004). Soil tests in boatyards throughout the Baltic Sea show that loose paint flakes resulting from hull scraping and washing 
during boat maintenance also results in high levels of toxins in the catchment (Eklund and Eklund 2014). Specific chemical formulations of paints are based on the salinity of the local waters. For instance, the Atlantic Ocean of Sweden and Norway contains higher salinity levels than the more brackish Baltic Sea waters. A higher salinity means an increase of marine fouling on boat hulls; the more toxic "hard" paints are only allowed for use on the Atlantic coasts of Baltic Sea countries.

While EU regulations cover product formulation and access, there is wide variation in local enforcement efforts, meaning "hard" paints are easily gotten in the countries boarding the Baltic Sea. There is also great variability how AF paints are handled by consumers. While antifouling maintenance practices are not undertaken every day, variance in environmental damage is related to maintenance practices, in particular inappropriate disposal of paint tins, failure to protect the ground during scraping and washing, and using "hard" antifouling paints. However, innovative market resources have recently been developed to serve the cause of greater sustainability. These include product and service innovations such as non-leaching silicone paints, scraping rugs installed in boat slips, scrubbers to manually scrape barnacles from the hull and stationary boat washers akin to the terra firma car wash. Multiple AF practice configurations arise from this assortment of macro level actors.

\section{Antifouling Practices}

Competence in the AF practice is a combination of practical skills and knowledge, the ability to handle the boat during storms or other unexpected scenarios, i.e., the ability to care for one's boat, passengers and crew. The boating community fosters a specific do-it-yourself (DIY) ethos 
and practical knowledge usually acquired from generations of experience and community involvement.

The steps of antifouling are the same for all competent boat owners. Put simply, a common competent painting practice is as follows. In the spring, the boat hull is prepared for painting. This entails cleaning and washing the boat hull with either a high-pressure hose or a bucket and sponge. After the washing procedure, loose paint flakes are removed from the hull with sandpaper to ensure a smooth surface. Next either one or two layers of AF paint are applied. The number of layers depends on the strength of the bio-fouling in where the boat is kept as well as on the condition of the boat hull. Painting rarely occurs during the summer boating season. Only if maneuverability problems or some visible fouling occurs do owners get in the water to clean the boat or brush the hull from the deck. In the fall, the boats are lifted and the boat hull is again washed with high pressure hosing or a sponge to remove bio-fouling. The boats are then stored on dry land in preparation for the freezing winter weather to come.

Practice configurations differ in part by the different materials used during the preparation on the boat hull, which can make the product use more or less sustainable. In addition to the boat, the sea, and the human bodies carrying out the maintenance practice, material elements of $\mathrm{AF}$ practice include the $\mathrm{AF}$ paint itself, brushes, tarps and other equipment used in maintenance, rules and regulations guiding or restricting the activity, as well as the overall marina infrastructure including recycling bins for waste management. The EU, local laws, enforcement of regulations and the boat community values also contribute to product use sustainability. Some boatyards provide proper disposal options for toxic AF paint containers. Others do not. Material resources such as recycling bins and toxic waste management systems encourages sustainable behavior. Thus, the boat wash area, as a part of marina infrastructure can 
either hinder or facilitate sustainable practices. High-pressure washing, the less sustainable option, is offered at some boat yards while some boaters only have access to handwashing materials, such as buckets and sponges. Likewise, collecting the paint scrapes with either a plastic sheet under the boat or by using a scraper connected to an industrial vacuum cleaner can prevent paint flakes from being washed on to the ground, the catchment and eventually the sea. In some boat yards the wash water goes directly into the catchment without any filtering, while other boat yards have a filtering system to mitigate the likelihood of toxins reaching the sea. Taken together, existing infrastructures and institutional actions, e.g., high-pressure hosing, wash water collection, effective waste management, regulatory enforcement, along with a variety of material options shape the AF practice.

-- Insert Figure 1 here --

\section{Practice Configurations}

We identified four configurations of use practices: The Proper Boater, the Opportunist, the Green Boater, and the Negotiator. Practice configuration variability (e.g., Hui 2017) has direct consequences on the environmental impact of paint use. Configuration elements include ways the boat is prepared for painting, the type of paint used, ways paints are applied, how much paint is applied, how often paint is applied, and disposal of paint packaging and waste water management. Variation among these practice configurations, along with regulations, infrastructure and community norms, mitigate or enhance sustainable product use. Individual boat owners do not necessarily fully participate in all aspects of any given configuration. This 
typology serves to organize maintenance options into discernable configurations, demonstrating how a range of practice elements leads to more or less sustainability.

The most common configuration is the Proper Boater. They follow local customs and boat club rules with respect to preparing the hull. They follow manufacturer recommendations and use two coats of paint every year. Their focus on the performance of the boat not necessarily concerns for excessive toxicity in the paint thus the outcomes of their practices may be less sustainable than other configurations. The least sustainable is the Opportunist, who maximizes time and material resources without regard for regulations, applying banned "hard" paints without the benefit of traps or sponge washing the hull to limit paint chips in the catchment. Green Boaters espouse sustainable values, focusing their efforts on limiting human-caused environmental degradation, yet often skirting the most sustainable consumption choices. This configuration is also most akin to the Proper Boater. The Negotiator configuration occupies the most sustainable end of the continuum. They use less paint than manufactures recommend, diluting the paint with water, only painting the patches that need painting, only painting one layer, and sometimes only every other year. Some Negotiators seek out new technical innovations, braving social tensions for forgoing painting practices and traditions all together.

\section{The Proper Boater}

The most common practice configuration, the Proper Boater, balances economic, time, social and aesthetic values in the pursuit of boat owner excellence. All other configurations are examined with respect to Proper Boater practices because the Proper Boater configuration represents the traditional AF practices expected in boat communities. 


\section{Exhibiting competence}

A Proper Boater is a competent practitioner with a well-maintained boat. Competent boating includes not only properly handling of the boat in use, but also attention to boating community norms that dictate that a well-maintained boat includes a clean boat hull, free from marine biofouling. This is normally achieved by careful cleaning of the hull and application of toxic antifouling paint according to manufacturer recommendations of two coats and re-painting each year. In short, the Proper Boater follows the boat community's norms that closely follow the manufacturers' instructions. Painting with AF paint is the most common marine fouling prevention method among boat owners. As Johan explains, "It's not a rocket science. The boat needs to be prepared every year... (using) standard techniques." Johan takes the AF practices for granted. He does not see a need to question the practice.

Institutional actors and boating community ethos contribute to the Proper Boater configuration exacting competences such as regulations and shared learning, materials such as infrastructure support and market resources, and meanings by creating a common understanding of being a Proper Boater. Within this practice configuration we find a complex inter-relatedness of different types of symbolic meanings with sustainability that arise from boating as an outdoor activity and they culture defining the Proper Boater.

For Proper Boaters, boating is not just a hobby, but a way of life. Toxic paints are "heroic actors" for Proper Boaters, providing a proven way of managing "barnacles (which are) very bad; (we) need to get rid of them.” These boaters use toxic AF paints 1) as the easiest and cheapest way to prevent fouling; 2) to gain optimal efficiency in the water in terms of speed and 
maneuverability; and 3) to have or maintain a clean boat for aesthetic reasons. These motivations are in turn linked to: 1) the enjoyment and ease of maintenance work; 2) relaxation as the main goal and purpose of boating; and 3) ownership, commitment and pride signaled by a clean, wellmaintained and kept boat. Thus, in terms of sustainability, the Proper Boater prioritizes boat performance over environmental concerns. The achievement of safety, reaching optimal efficiency and reducing drag, underscore the Proper Boater's sense of competency and freedom.

\section{Learning the ropes}

Antifouling practices are central to the of feeling of safety during boating. The sea can be dangerous and constantly testing boat owners' skills. Therefore, boat owners emphasize the need to be able on trust the boat. Eveliina describes the relatively unpleasant but necessary task of checking the boat hull for holes while painting, "Testing the boat for the holes in the bottom is everything but fun as each hole needs to be tested for being in proper shape, including those with valves etc." The task is inherently unpleasant as it brings up the feelings of anxiety. The most horrifying result of failing to properly prepare and then paint the hull is later finding holes in the boat. For boat owners, proper antifouling is equal to safety and they do not want any compromises with respect to safety when on the water.

The boat community teaches necessary competencies and sets certain aesthetic standards for boat hulls. Boaters socialize and learn the practices of boat maintenance through observation and interaction with other community members. Most boat owners belong to a marina boat club where they house and maintain their boats. Professional boat cleaning companies come to the boatyards to life and wash the boats making the vessel ready for painting. Boats at any given 
marina are usually lifted over the course of a couple of days, and all boat owners having their boats lifted on the same day are present. One such day Tauno quickly learned the meaning of having clean boat hull:

When they lifted the boat, the hull was full of slime but not barnacles. One guy waiting for his boat to be lifted commented on the boat hull saying 'wow you have a garden growing on your boat hull!' Tauno responded looking a little ashamed: “yeah that's not looking nice... (Field note Helsinki spring 2016).

Tauno's boat stood out from other boats for his "garden" among the other boats, none of which had any algae. Even though the algae on Tauno's boat was less of a violation than would be barnacle encrusted craft, he felt he got a "bad eye" from others at the marina.

While the purpose of AF paint is as Marko puts it to "have the boat hull as smooth as possible" for reducing drag, aesthetics also figures in the meaning of having a well-maintained boat hull. Jaakko explains, "It is not only the functionality why I maintain it (the boat). It is also the aesthetics that matters." Some boat owners chose paint color that fits with the appearance of the boat. Eveliina notes:

We use paint called Hempel's Mille, we have painted the lower part in white, and then the upper part in blue. I think we are the only ones in our club having white, most have blue or red, I do not know why. I think white looks really good as well. 
Laura mentioned the community's impact on their choice to paint, for both anti-fouling and aesthetic needs, "When we were looking, how much we could pay [for the boat] and how much we would need for the repaint and changing the color we asked a lot of people around here of which paint are you using."

Proper Boater configuration exemplifies traditional community norms and values. Many boaters share fond memories of their parents painting the family boat, albeit with toxic paint. Youngsters often participated, as Rafael recalls, "I have painted boat[s] since I was nine years old."

The Opportunist

The Opportunist adheres to the Proper Boater meaning of a clean hull, and does so by maximizing time and material resources without regard for regulations. These boaters also flout EU regulations by applying banned "hard" paints or prepare the hull without the benefit of tarps, water filtration systems or sponge washing to limit paint chips in the catchment. While not violating the Proper Boater ethos of care for the boat, this practice configuration is the least environmentally sustainable.

\section{Maximizing expedience}

Opportunistic boaters point to the actions of institutional actors as the source of opportunity for their "bad" behavior, effectively outsourcing morality (Byrkjeflot 2001). For instance, marinas which fail to offer vacuum systems, water filtration or proper waste disposal options facilitate 
Opportunists' maximizing goals. Devoid of regulation enforcement, retailers sell paints indiscriminately, providing an opportunity for illegal consumption of banned paints. Lars explains, "[It's] in the regulations from the authorities (Swedish Chemicals Agency) here, you should just use, approved paint. Other paints are not allowed. But as long as you can find them on the market..."

Jacob adds:

"To be honest, I use (excessively toxic) paint imported from Norway, probably I shouldn't have told you this. But [it is] common, after I have painted the boat with this paint, [there is] no need to redo it on yearly bases..."

Hans concurs that "...hard (most toxic) paint is necessary for boat performance." Some recall the TBT paint formula banned by 1989 EU legislation as evidence of the safety of current paint formulations. As Per explains, “They can't sell the real, hard stuff anymore. So, it's [the new paint is] ...more eco-friendly," and Rafael adds "I think copper is not so uh, poisonous as other types [...] because the authorities have said, 'you can use this painting.' and I must trust on (sic) them." In these ways, the actions of institutional actors lead to normalizing the still toxic paints and maintenance practices, even to the point making paints developed after 1989 seem benign. Even though the regulations limit the selling and thereafter usage of "hard" AF paint, zinc and copper remain under-regulated (BONUS 2014), leading to the perception that these chemicals are safe at any level. Consumers looking to maximize their time and resource efforts forgo the 
rule of law, placing the onus for "hard" paint availability on the market. The opportunity to consume "hard" paints also serves their aesthetic sensibilities:

Miika told that he had put toxic paint on the boat hull but mainly because of aesthetics. He said that he wasn't quite sure whether it was necessary because he had put hard paint on the hull. Last year he didn’t put anything (Field notes, Helsinki, Spring 2015).

\section{$\underline{\text { Regulation and enforcement variations }}$}

The lack of regulation and enforcement offer pathways for the Opportunists to carry on unsustainable AF practices. Boat hull maintenance is regulated and enforced to different degrees across the research sites partly due to the different geographical environments but mainly due to different interpretations of the regulations and cultural variations. Illustrating the variances and their relations to sustainable and unsustainable practices is instructive. The data from the Kiel, Germany boatyard demonstrates the most profound efforts to limit environmental toxicity through a combination of sustainability-enhancing infrastructure conditions and effective regulatory framework supported by cultural factors, in particular adherence to rules. We observed some boat owners in the marina taking great care, using a plastic sheet under the boat hull when they undertake hull maintenance work such as painting and scraping. These activities are mandated by local "marina rules", where non-compliance has significant financial consequences with fines of up to $100 €$ imposed for violations. Karl notes how marina rules are enforced by community surveillance and government authorities, stating "we control each other, but there are black sheep everywhere...the water police also comes (sic) by and controls boat 
owners, also fines are possible." German boat owners demonstrate mutual control to maintain sustainable outcomes, yet Opportunistic Boaters privilege efficiency, enduring the scorn of their Proper Boater neighbors. Authorities visit the marinas regularly, yet "black sheep" boaters remain undeterred by the threat of fines or in extreme cases, ouster from the marina. Waste management plans are also quite strict and consistently enforced, and marinas provide separate bins for hazardous waste on site. While the German authorities are aware of the unsustainable practices involved with boat maintenance and readily imposed fines act as deterrents to irresponsible maintenance, violations do occur.

Along with a ban on the use of "hard" paint on the Baltic coast, the Swedish government has regulations in place which require marinas to undertake wash water management. Various municipalities in Sweden regulate the collection of wash water differently. Since 2009 Gothenburg marinas with over 50 boat berths have been required to install a wash water collection or face fines up to $10,000 €$. Unfortunately, the enforcement of these rules is not very strong. The ease with which Opportunists circumvent regulations is pronounced. As Hans notes, “...yeah, we clean all the boats on (the same) spot with high pressure water. Unfortunately, the water goes on the sea..." Others blame the government for being too focused on amounts of copper rather than practical information about product use and the harmful effects of AF paint. Lars complained, “... authorities in Sweden regarding boating [provide more] nice figures of how much copper is sold as a biocide that go[es] into antifouling paint." Lars implies there is negligible governmental concern regarding the environmental impact of these paints. Even if the harbormaster finds illegal paints being used in the marina, there is nothing he can do to prevent or sanction the boaters using banned products. Like many respondents, Lars contends too much of the responsibility for sustainability is placed on the consumer. This is of little help to the 
boaters who wants to avoid opportunism and looks to the authorities to shift their focus from awareness building to consumer usage practices.

Finland offers little regulation or enforcement of AF paint use beyond the $1989 \mathrm{EU}$ regulation. While private boat clubs provide some education for members, public marinas engage in little monitoring of boater behavior, and there are few if any regulations specific to $\mathrm{AF}$ practices. There are no sanctions or fees in place, allowing unsustainable painting practices go on unhindered. Waste recycling or adequate toxic waste bins are not regularly provided and boaters tend to leave used paint tins lying around the marina. Supportive waste water management infrastructure in public marinas is largely lacking. Most boat hulls are washed with high pressure hoses which both cleans the boat and removes the flecks of old paint. Finnish authorities find this practice unproblematic, citing the clean hull and time and effort resource efficiencies. Harbormaster Kalle from Helsinki claims:

The high-pressure hosing has its advantages. The boat hull shines after. All these boats (points at the boats) have been washed with high pressure hosing. I don't see it as a problem. It just cleans the hull well without an extra effort.

Marine scientific reports confirm higher levels of copper in marina environments with the least supportive infrastructures, least surveillance by harbor masters and other boat owners, and greater accessibility to higher copper content paints (Eklund et al. 2016). Taken in combination, these institutional and consumer practice elements constitute the Opportunist configuration.

\section{The Green Boater}


Most boaters consider themselves to be environmentally conscious, yet Green Boaters claim greater sensitivity to sustainability in their maintenance practices. While they share a common knowledge of the deteriorating condition of the Baltic Sea, in many ways their actions are only slightly more environmentally sustainable than those of the Proper Boater. Where the Proper Boater follows the norms and manufacturer's instructions and aims for the most efficient boating, the Green Boater acknowledges the importance of environmental sustainability.

\section{Perceptions of harm and sustainability}

Self-proclaimed Green Boaters may define sustainability somewhat narrowly, citing a general understanding of the concept as the harm caused by $\mathrm{CO}_{2}$ emission related to fuel consumption and one's carbon footprint (Yngfeld 2016). For boaters, fuel consumption - and importantly, its reduction - is directly linked to using AF paint as harm from fuel consumption can be mitigated by regular painting of the boat hull to reduce drag. Sailboat owners in particular consider themselves to be more sustainable in their consumption in contrast to motorboat owners: sailboats use less fuel, thereby causing less environmental harm. For some boaters, the fuel economy of sailing was the main reason to choose a sailboat over a motorboat. Inka explains, "First of all, it [using a sailboat] is much more environmental (sic) friendly compared to for example some big motorboat that fuels up liter even hundreds of liters of petrol." This point illustrates the problematic of the green consumer ethos: while environmentally conscious consumers may recycle more, they still consume, only differently, largely due to no attention being paid to the level and type of consumption (Connolly and Prothero 2003). 
Green Boaters also define unsustainable behavior as inappropriate disposal behaviors at both the institutional and consumer levels. They cite negative effects of harmful industrial effluence from Russia, pollution from the agriculture, and other boaters leaving trash behind in the archipelago. As Iiris explains, "It is very important to me that everyone deals with their own left-over stuff garbage [in the archipelago]." Litter is easily understandable form of unsustainable behavior, yet the environmental harm of AF paints cannot be seen. Convincing Green Boaters that AF paint presents an environmental hazard depends in part on practical empiricism. Emma notes that if there was a "pool of dead fish" around her boat, it would make the issue more tangible. Information of the actual, physical harm caused on the marine life by paints leaching toxins into water not readily available. Pekka notes how there is no explicit knowledge being disseminated about "what your $[\mathrm{AF}]$ paint does to the marine life." While some boat clubs have practical guides and information regarding more sustainable maintenance available for their members, non-members feel they don't have easy access to this information. As Anne notes that it's “because I am not a member [of a boat club], I don't get any information.” The responsibility for acquiring information about sustainability and AF paint is placed with the individual boater.

The detrimental environmental effects of AF paint often fall outside the scope of the Green Boater's understanding harm. When questioned about a ban of highly toxic paints in a Finnish boatyard due to environmental reasons, Tim commented, "I think it [the ban] is a good thing," however, he mitigates his critique with a cavate:

I wonder if the leisure boats pollute so much. I mean I see that the Gulf of Finland is in a bad condition but if you consider how much comes from the runoff from the agriculture. .... and those are not any light toxics. So, when you consider these 
toxics leaking from the boat hulls the leakage is minor because you only apply a thin layer and the thin layer hasn't even eroded entirely when the boat is lifted. But every little thing has an influence. So .in that sense I think it's good that they try organizing [the practice] in the best possible way.

Tim exemplifies a conflicted understanding of sustainability. While he's concerned about the toxicity of AF paints and thinks something ought to be done, he focuses on industrial pollution as a more problematic.

The Negotiator

The Negotiator configuration produces the most sustainable antifouling outcomes. Where the Opportunist outsources morality into the authorities, the Negotiator shows greater agency in separating from the traditional AF practice. This boater is the most sustainably conscious navigating between different AF practice materials for more sustainable options. Many new market entrants provide a variety options for those seeking to avoid AF paints all together. These include biocide-free paints or paint-free mechanical methods.

\section{Circumventing manufacturers' recommendations}

Negotiator Boaters use AF paints but in ways that cause relatively less environmental harm. AF manufacturers' recommended use is to paint two layers every year, yet Negotiators actively circumvent these recommendations. These boaters engage in tactics of using less paint 
by: 1) painting only one layer per year; 2) painting only the patches that need painting; or 3) painting only every other year. Sven explains, "If you can make a thin layer it, you can use it longer. So that is little cheaper. And it works...(I) paint just always some parts." Some use a combination of these three tactics, while others add manual brushing or sponging frequently during the boating season to their practices. Others forgo painting all together, maintaining that as long as the boat is frequently used, barnacles present no real problem.

This behavior illustrates competence among the boaters expressed in a resourceful way of engaging with existing practices. Whether motivated by economic or creative desires, painting less generates more sustainable outcomes. Negotiator Boaters engage in their own tactics (De Certeau 1984) which allow them to paint less. Skilled boaters know their vessel, characteristics fo the paint and the Baltic Sea. Painting less requires reflexivity and considerations of overall sustainability and weighing the available options. As a consumer tactic (e.g., Casey, Lichrou, and O’Malley 2017) Negotiators actively circumvent the traditional practices. In these ways, the dimensions of competence and meaning clearly intertwined with materiality combine to results in more sustainable outcomes. It requires resourcefullness and trust in one's own capabilities and knowledge in considering the actual need versus the advertised anti-fouling effects.

Boaters in this configuration may also choose biocide-free paints, thus maintaining some practice elements of the Proper Boater ethos, with important differences. The innovation of biocide-free paints means less frequent re-painting. Biocide-free paints use silicon-based and Teflon-like coatings rather than the leaching of zinc and copper to keep bio-fouling organisms at bay. Silicone paints have a slippery surface and are designed to make it difficult for marine organisms to attach to the boat hull. These comparatively expensive silicone paints may be used 
in combination with hand cleaning devices, such as brushes to clean the hull when barnacles attempt to attach.

\section{Innovative technologies modifying practice}

Institutional actors provide materiality and innovative technologies that modify practice outcomes or disrupt them altogether. Paint-free mechanical antifouling solutions include boat washers, boat lifts, hull covers and scrapers. The popular boat washer is similar to a car wash, adapted for washing boats in the water. Rotating big plastic brushes clean the boat hull and the marine fouling and paint flakes are collected in a basin under the boat wash. The cleaning process uses no biocides and takes around 20 minutes. Baltic Sea boats need to be washed two to three times each season.

Another type of innovation is the personal boat lift. These devices are permanently installed at each owner's slips. The boater steers the craft into position and the lift is used to haul the boat straight up and completely out of the water. The boat remains suspended above the water until the next use.

The third category of paint-free options is the physical scraping device. These include hull covers and hand-held broom-like tools. Hull covers sporting hard plastic spines are installed in individual boat slips. The spines scrape the hull each time the boat leaves and returns to the slip, thereby physically scraping bio-fouling organisms from the bottom of the boat. The company notes that movement from wind, waves and currents help the hull "stay clean even when the boat is not in use" (Seaboost 2017). 
The final paint-free device is a long-handled brush which allows the owner to clean the hull standing alongside; there is no need to lift the boat from the water to scrape the bio-fouling off the hull (Scrubbis 2017). Room to stock large, physical scraping devices means these nonpaint options are rarely available at marine supply retailers so Negotiators must make purchases at annual boat fairs or online. This barrier to availability inadvertently reifies the traditional AF paint practice configuration.

\section{Barriers to innovation: Grappling with tradition}

Changing to a new more sustainable antifouling method threatens the traditional practices. New innovations change the way how antifouling is done, circumvent the do-it-yourself(DIY) ethos and limit boat maintenance time with family and friends and the social activities associated. In these ways, they threaten the materiality and meaning of the Proper Boater configuration.Many boaters choose to remain loyal to their time and labor-intensive unsustainable practices of AF paint maintenance even though new innovations make the antifouling procedure more sustainable and easier.

Boaters hold on to their AF paint practices for several reasons. The first of these is tradition. The Proper Boater configuration is indicative of the way boaters learned antifouling from their parents, friends and fellow boaters. These practices can be well ingrained in the consumption community as Björn notes "I think it's [maintenance practices are] rather traditional, boat people are rather traditional." Pelle concurs, "You learn [anti-fouling practices] from your neighbors..." Families not only take part in boating activities, but also in boat maintenance. Boaters look forward to the traditional painting times as an activity to do with their 
loved ones. One woman in Gothenburg emphasizes the importance of the social aspect of painting and explains that she has this tradition to do the maintenance together with her husband and further highlights "it is fun, to do it together." Mauno from Finland elucidates "Autumn and spring maintenances I do pretty much with my wife Anne.” Springtime boat lifting days in marinas are perfect places to connect with other boaters and socialize. As Heikki reflects, "boat maintenance is a social event. Boaters help each other with for example lifting the boat (refers to lifting of the boat during spring maintenance)."

Alfie concurs:

Now the summer season is the important one, having to do with... well you did visit the lifting ...a sort of social event it is, it has to do with social aspect as well. The lifting and launching are of some intensity, lots of things going on, lots of people gathering.

Another barrier to the embracing Negotiator configuration is a strong (DIY) ethos among boat owners. Hiring service companies is expensive and many boaters really enjoy working with their hands and making repairs on the boat. Confidence in boating performance and marine safety comes from a deep knowledge that the work done is properly and completely: 70 year old Jörg still maintains both the mechanical facilities and the hull himself. The DIY ethos also includes competency as a shopper. The costs for paint depend on the size of the boat and especially how many layers of paint are applied to the boat, and Laura takes pride in her family's competence and thrift: 
We're using, (white paint) from Biltema. A cheap one. But it's working on our boat....

[We like] the efficiency and also the price, because it's really expensive to paint the boat, every year.... I think about 600 SEK [58€] every year.

Embracing traditional practices serves to reproduce normalized and environmentally harmful practices. On the other hand, consumer tactics of painting less, requires reflexivity, resourcefulness, knowledge of the boat and trust in one's ability in knowing how and when to paint less, and rejecting manufacturers' authority, in short subverting normalized maintenance practice by way of painting less has a positive effect on sustainability in terms of product use. Both tactical behaviors, however, draw on historical consumer knowledge of paints and their characteristics, and build on knowing one's boat, how it behaves in the given sea environment vis-à-vis barnacles and fouling.

Competence can have a variety sustainability impact. It follows that competency cannot be defined solely in terms of increased knowledge or improved skill in terms of increased sustainably and awareness. Rather, these are largely determined by the desired outcome sought by the individual boater and tied to practical intelligibility of the individual. Unfortunately, the best outcome often translates into what maintenance solution most effectively keeps off the barnacles, materializes as more toxic paints.

\section{Discussion}

Our findings demonstrate how macro level institutional actors can affect consumer practice configuration variance during product use. A practice theory lens illuminates how thinking of 
sustainability in terms of a macro-micro divide may be a false dichotomy (e.g., Nicolini 2017a, 2017b). Macro level actors, in particular regulations with enforcement, marketplace resources and infrastructure effecting competence, and materiality and meaning in consumer practices, provide options for more or less overall sustainability in product use.

Varying practice configurations illustrate the ways rules as meaning, both macro level institutional regulations and micro level cultural expectations, shape consumer practices. They also illuminate the ways marketplace options as materiality, in both stagnated products and innovations, provide opportunity for variance. And finally, practice configurations illuminate the ways consumer ethos as competence is tied to both tradition and change vis-a-vis consumer resourcefulness. This study illuminates the ways formal regulations, along with cultural and social rules, enact meaning in practice configurations. For the Opportunists, rules were of little consequence, made to be bent or broken in pursuit of a clean hull. The hubris of exceptionalism in this configuration reminds policy makers that rules are only useful if they are indeed enforced.

Marketplace resources can also have a great impact on consumer use and sustainability, if institutions truly act in good faith. However, putting faith in institutional actors does not necessarily guarantee professed sustainability outcomes. Companies sometimes deliberately violate environmental regulations while presenting their products as compliant. The US indictment of former Volkswagen CEO Martin Winterkorn and five other executives on charges of conspiracy and fraud in connections with years-long emissions scheme services as caution to consumer who put their faith in corporations (NPR 2018). Not all boaters trust manufacturer recommended use of products is best for their circumstances. Some use the products as directed while others creatively circumvent manufacturer authority. While all boaters work toward clean hulls to minimize drag, and increase fuel economy and maneuverability for safety, the use of 
toxic paint as a traditional marker of competency is challenged by non-toxic product innovations and associated anti-fouling methods.

Researchers have long called for addressing nexus of sustainability and marketing at the macro level. Some take a broad societal perspective, calling for dramatic, system level change (e.g., Assadourian 2010; Kilbourne, McDonagh, and Prothero 1997; Nason 2006) while others focus on changes in the marcomarketing discipline itself (Mitchell, Wooliscroft, and Higham 2010), suggesting increased efforts to identify "optimal regulatory frameworks for governing the role of marketing" (Van Dam and Apeldoorn 1996, p. 45), responsibilities of a variety of social actors (Schaefer and Crane 2005), resources for scholars (Samuel and Peattie 2016; Simkins and Peterson 2016) and calls for (Kilbourne 2004; Varey 2010) and critiques of (Burroughs 2010) a re-thinking of marketing in its entirety.

Others note how the responsibility for sustainability has been shifting from governmental actors to corporations (Humphreys 2014) and consumers (Giesler and Veresiu 2014). Consumers participate in sustainability in micro level practices, yet in aggregate enact macro impact (Dolan 2002; Casey, Lichrou, and O'Malley 2017). Consumer behavior and (un)sustainable outcomes has formed the basis for much macromarketing scholarship (e.g., Benton 2015; Guillard and Roux 2014), in particular addressing culture and consumption ideologies (Dalpian, da Silveira, and Rossi 2015; Thøgersen 2010). This paper adds this literature by demonstrating connections between macromarketing and consumer culture theory through the examination of sustainability in product use.

\section{Implications for Macromarketing and Sustainability}


Overall sustainability occurs only partially in the formulation of the product; regulation of distribution also plays an important role. We demonstrate the need for institutional actors to regulate distribution of the best AF paint formulas for regional sea water salinity. It is not uncommon for industries to limit access to dangerous goods at the level of distribution, for example, alcohol and cigarettes for youngsters, psychotropic drugs for adults, and explosives for road and building construction teams.

Maintenance work is essentially using products and services to protect and repair other products. While many consumer products are held in closed technical loops, i.e., the cotton cannot be separated from the garment, maintenance products may be materially fluid, thus enacting different sustainability outcomes depending on use. It is at the confluence of governmental regulation, market resources and consumer practices that the meanings, materiality and competency in maintenance work allows for variance in environmental sustainability. Proper maintenance practices are enforced at the micro and meso levels via community surveillance of local norms. Without localized enforcement, macro level regulations are rendered relatively toothless.

Natural environments handle waste differently. Many pollutants are sequestered in the ground on land or dispersed in the atmosphere. Material consumer waste is visible, easily measured and handled by consumers on a daily basis. Although unseen, $\mathrm{CO}_{2}$ emissions are widely understood as harmful to the environment and human health. Yet rivers, lakes and seas are highly vulnerable to unseen waste, leaching from ground systems via rain, erosion and run off. Microplastics settle in the sediment and join the marine-human food chain (Hidalgo-Ruz et al. 2012). Chemical waste in AF paint disrupt the lives of benign marine animals (Krång and Dahlström 2006). The unseen nature of waste in water encourages a laissez-faire policy toward 
the seas which is only recently garnering attention, in part due to the massive, visible, Great Pacific Garbage Patch (Rios et al. 2010).

A tangible solution for the innovative product manufactures providing alternative methods for antifouling painting is to render the invisibility of harm to visible. Take the issue of runoff water from boat hulls during AF maintenance. Concerned stakeholders could bring the problem into view with an illustrative campaign showing how many toxins leak from the washing process by comparing boats sporting traditional AF paints versus boat hulls maintained with the alternative methods.

\section{Implications for Consumer Culture Theory and Sustainability}

Taking up Prothero et al.'s (2011) call for additional research into sustainable consumption, we demonstrate how consumer practices can lead to overall environmental impacts that are more or less sustainable. Sustainable marketing research has long history of focus on consumers (Fisk 1974; Webster 1975; Sassatelli, 2006, 2008), often placing the responsibility for overall success of a sustainable society in the hands of these actors alone. Changes in meaning, variety of competencies and provision of supporting materiality all go some ways toward more sustainable product use practices. Environmental impacts resulting from the effects of these variations (e.g., Hui 2017) demonstrate the value of context comparative practice theory analysis to uncover the degree to which product use sustainability can be supported by enabling infrastructure and regulations. Our research also highlights the importance of contextual idiosyncrasies and consumer realities for the successful understanding and application of sustainability policies and strategies. Akin to the difficulty of enacting a sustainable actor-network in textiles (e.g., 
Gustafsson, Hjelmgren, and Czarniawska 2015) and the social practice of food waste management (e.g., Southerton and Yates 2015), the combination of supporting infrastructure, enforced regulations, consumer resourcefulness and innovative market resources are important steps towards the most sustainable outcomes in service of a clean boat hull.

\section{Moving Toward Sustainable Consumption}

Boaters carefully maintains their vessels and many also proclaim a caring a great deal about the natural environment so integral to boating enjoyment. This care could be extended to include the sea in more profound ways. Previous studies have shown that when it comes to environmental problems, consumers tend to view these from a supply rather than a demand perspective (Connolly and Prothero 2003), making it difficult to achieve changes in behavior as long as change toward sustainability is expected to come about as a result of consumer responsibilization (Giesler and Veresiu 2014). It is possible that shaping the meaning (e.g., Shove, Pantzar, and Watson 2012) of harm, and what it means to be eco-friendly, as well as what sustainable consumption entails would result in desired changes in competence, that is, at the level of carrying out the maintenance practice. Adopting a "consumption as communication value" perspective, Connolly and Prothero (2003, p. 275) note how consumers buy into "a particular image in their consumption practices connected to the meanings of their consumption that are derived from the communication value they attach to commodities." In view of the full consumption cycle, one of the aims is to encourage people to consume less, and to do so we must employ existing commodity discourse (Connolly and Prothero 2003). 
Our findings demonstrate nuances in practice theory and sustainable consumption which suggest macro level efforts towards change are also warranted. To study sustainable consumption, scholars have called for more studies aimed at understanding the social structure (Spaargaren 2003; Shove 2010a) and particularly "the significance of cultural conditions of possibility in guiding and constraining consumers' ways of being and acting in the world" (Moisander, Valtonen, and Hirsto 2009, p. 343). When considering how to change behavior regarding sustainable consumption, the focus should be on the wider perspective instead of a narrow concern (Sahakian and Wilhite 2013; Welch, forthcoming). Kilbourne, McDonagh, and Prothero (1997) have long argued that changing the dominant social paradigm, the technological, political and economic benefits and costs of consumption from a macromarketing perspective is necessary for systemic change toward a sustainable future. We concur and offer Holt's (2012) more recent suggestion that we acknowledge and overcome "the structures holding unsustainable consumption in place" (p. 252) as a way to truly move markets toward greater sustainability. For boat maintenance practices, these structures are the institutional actors at the macro level, i.e., paint manufacturers, innovative products and regulations at all levels of governance, from the European Union to local municipalities. Holt claims that thinking in terms of what he calls the “ethical values paradigm" (p. 237) will not result in achieving more sustainable consumption patterns. Instead he offers a "market constructionist paradigm" (p. 237) facing sustainability "market by market." Holt (2012) recommends a wholesale examination of "ideological lock-ins" which un-couples consumerist values from unsustainable consumption behavior. Our findings support this rationale, and recommend practice theory elements of meanings, materials and competence as sites of intervention for change at the market level. We suggest future research 
take these missives to heart and expand extant research to non-Western contexts to further examine the role of macro forces on maintenance practice configurations.

\section{References}

Arnould, Eric J. and Craig J. Thompson (2005), “Consumer Culture Theory (CCT), Twenty Years of Research," Journal of Consumer Research, 31(4), 868-882.

Arnould, Eric J. and Melanie Wallendorf (1994), “Market-Oriented Ethnography, Interpretation Building and Marketing Strategy Formulation," Journal of Marketing Research, 31(4), 484-504.

Arnold, Stephen J. and Eileen Fischer (1994), "Hermeneutics and consumer research." Journal of Consumer Research, 21 (1), 55-70.

Assadourian, Erik (2010), “Transforming Cultures, From Consumerism to Sustainability,” Journal of Macromarketing, 30(2), 186-191.

Baldwin, David H., Jason F. Sandahl, Jana S. Labenia, and Nathaniel L. Scholz (2003) "Sublethal Effects of Copper on Coho Salmon: Impacts on Non-overlapping Receptor Pathways in the Peripheral Olfactory Nervous System," Environmental Toxicology and Chemistry, 22(10), 2266-2274.

Benton Jr, Raymond (2015), Reduce, Reuse, Recycle... and Refuse. Journal of Macromarketing, $35(1), 111-122$. 
Belk, Russel W., Fischer Eillen, and Kozinets, Robert V. (2012), Qualitative Consumer and Marketing Research, London:Sage.

Bertilsson, Jon (2015), “The Cynicism of Consumer Morality," Consumption Markets \& Culture, 18(5), 447-467.

Bourdieu, Pierre (1977), Outline of a Theory of Practice. Translated by Richard Nice. Cambridge: Cambridge University Press.

BPR (1989), Regulation (EU) No 528/2012 of the European Parliament and of the Council of 22 May 2012 concerning the making available on the market and use of biocidal products (accessed June 22, 2018), [available at https://eur-lex.europa.eu/legalcontent/EN/TXT/?qid=1401798094770\&uri=CELEX:32012R0528].

BONUS Change (2014), "Changing Antifouling Practices for Leisure Boats in the Baltic Sea", (accessed June 2015), [available at https://www.bonusportal.org/projects/viable_ecosystem_2014-2018/change].

Brosius, Nina, Karen V. Fernandez, and Hélène Cherrier (2013), "Re-acquiring Consumer Waste, Treasure in Our Trash?," Journal of Public Policy and Marketing, 32(2), 286-301. Bulkeley, Harriet and Nicky Gregson (2009), "Crossing the Threshold, Municipal Waste Policy and Household Waste Generation," Environment and Planning A, 41, 929-945.

Burroughs, James E. (2010), “Can Consumer Culture Be Contained? Comment on "Marketing Means and Ends for a Sustainable Society', Journal of Macromarketing, 30(2), 127-132. Byrkjeflot, Haldor (2001), "The Nordic Model of Democracy and Management.," The Democratic Challenge to Capitalism: Management and Democracy in the Nordic Countries, 19-45.

Cao, De-ju, Pan-pan Xie, Juan-wei Deng, Hui-min Zhang, Ru-xiao Ma, Cheng Liu, Ren-jing 
Liu, Yue-gan Liang, Hao Li, and Xiao-dong Shi (2015), "Effects of Cu2+ and Zn2+ on Growth and Physiological Characteristics of Green Algae, Cladophora," Environmental Science and Pollution Research, 22 (21), 16535-16541.

Casey, Katherine, Maria Lichrou, and Lisa O’Malley (2017), “Unveiling Everyday Reflexivity Tactics in a Sustainable Community," Journal of Macromarketing, 37(3), 227-239.

Chatzidakis, Andreas, Pauline Maclaran, and Alan Bradshaw (2012), "Heterotopian Space and the Utopics of Ethical and Green Consumption," Journal of Marketing Management, 28 (3-4), 494-515.

Cherrier, Hélène (2010), "Custodian behavior, A Material Expression of Anti-Consumerism," Consumption Markets and Culture, 13(3), 259-272.

Cohen, Maurie. J. (2006), "Sustainable Consumption Research as Democratic Expertise," Journal of Consumer Policy, 29(1), 67-77.

Connolly, John and Andrea Prothero (2003), "Sustainable Consumption, Consumption, Consumers and the Commodity Discourse," Consumption Markets \& Culture, 6(4), 275291.

Dalpian, Paulo RC., Teniza da Silveira, and Carlos AV Rossi, (2015), “One Less Car” The Collective Initiative Toward Sustainability," Journal of Macromarketing, 35(1), 99-110.

De Certeau, Michel (1984), The Practice of Everyday Life, Berkeley: University of California Press.

Devinney, T. M., Pat Auger, and Giana M. Eckhardt (2010), The Myth of the Ethical Consumer, Cambridge: Cambridge University Press.

Dolan, Paddy (2002), “The Sustainability of 'Sustainable Consumption'," Journal of Macromarketing, 22(2), 170-181. 
Eklund, Britta and David Eklund (2014), "Pleasure Boatyard Soils are Often Highly Contaminated," Environmental Management, 53(5), 930-946.

Eklund, Britta, Lisen Johansson, and Erik Ytreberg (2014), “Contamination of a Boatyard for Maintenance of Pleasure Boats," Journal of Soils and Sediments, 14(5), 955-967.

Eklund, Britta, Erik Ytreberg, Maria Lagerström, and Ann-Kristin Eriksson (2016), "Report on Testing of an XRF-Analyzer to Detect Metals and TBT on Boat Hulls, in Boat Yard Soil and Harbor Sediment for Future Use in Regulatory Supervision of Boats And Boat Yards,” BONUS CHANGE. White paper report.

Ekström, Karin (2014), Waste Management and Sustainable Consumption, Reflection on Consumer Waste, London: Routledge.

Fisk, George (1974), Marketing and the Ecological Crisis, New York: Harper \& Row.

Gherardi, Silvia (2017), "Sociomateriality in Posthuman Practice Theory," in The Nexus of Practices, Allison Hui, Theodore Schatzki and Elizabeth Shove, eds. London: Routledge, $38-51$.

Giddens, Anthony (1984), The Constitution of Society, New York: Polity Press.

Giesler, Markus and Ela Veresiu (2014), "Creating the Responsible Consumer, Moralistic Governance Regimes and Consumer Subjectivity," Journal of Consumer Research, 41, $840-857$.

Goulding, Christina (2005), “Grounded Theory, Ethnography and Phenomenology, A Comparative Analysis of Three Qualitative Strategies for Marketing Research,” European Journal of Marketing, 39(3/4), 294-308. 
Guillard, Valérie and Dominique Roux (2014), "Macromarketing Issues on the Sidewalk: How "Gleaners" and "Disposers" (Re) Create a Sustainable Economy," Journal of Macromarketing, 34(3), 291-312.

Gupta, Shruit S. and Denise T. Ogden (2009), “To Buy or Not to Buy? A Social Dilemma Perspective on Green Buying,” Journal of Consumer Marketing, 26(6), 376-391.

Gustafsson, Eva, Daniel Hjelmgren, and Barbara Czarniawska (2015), "Cloth Loop: An attempt to Construct an Actor-Network," in Waste Management and Sustainable Consumption: Reflections on Consumer Waste, Karin M. Esktröm ed. London: Routledge, 115-129.

Hand, Martin, Elizabeth Shove, and Dale Southerton (2005), "Explaining Showering, A Discussion of the Material, Conventional, and Temporal Dimensions of Practice," Sociological Research Online, 10(2), 1-13.

Hargreaves, Tom (2011), "Practicing Behaviour Change, Applying Social Practice Theory to Pro-Environmental Behaviour Change," Journal of Consumer Culture, 11(1), 79-99. Heiskanen, Eva and Mika Pantzar (1997), “Toward Sustainable Consumption, Two New Perspectives," Journal of Consumer Policy, 20(4), 409-442.

Hertwich, Edgarg (2005), "Life Cycle Approaches to Sustainable Consumption, A Critical Review," Environmental Science \& Technology, 39(13), 4673-4684.

Hidalgo-Ruz, Valeria, Lars Gutow, Richard C. Thompson, and Martin Thiel (2012), "Microplastics in the Marine Environment: A Review of the Methods Used for Identification and Quantification," Environmental Science \& Technology, 46(6), 30603075. 
Holt, Douglas B. (2012), “Constructing Sustainable Consumption, From Ethical Values to the Cultural Transformation of Unsustainable Markets," The ANNALS of the American Academy of Political and Social Science, 644(1), 236-255.

Hui, Allison (2017), "Variation and the Intersection of Practices," in The Nexus of Practices Allison Hui, Theodore Schatzki and Elizabeth Shove, eds. Routledge: London, 52-67. Humphreys, Ashlee (2014), "How is Sustainability Structured? The Discursive Life of Environmentalism," Journal of Macromarketing, 34(3), 265-281.

ISO.14040 (1997), Environmental Managements Life Cycle Assessments Principles and Framework; International Organization for Standardization, Geneva.

Jackson, Tim (2009), Prosperity Without Growth, Economics for a Finite Planet, London: Earthscan.

Jacoby, Jacob, Carol K. Berning, and Thomas F. Dietvorst (1977), "What About Disposition?," Journal of Marketing, 41, 22-28.

Jorgensen, Danny L. (1989), Participant Observation, A Methodology for Human Studies, London: Sage.

Kalverkamp, Matthias and Thorsten Raabe (2018), “Automotive Remanufacturing in the Circular Economy in Europe: Marketing System Challenges," Journal of Macromarketing, 38(1), 112-130.

Karlsson, Jenny and Britta Eklund (2004), "New Biocide-Free Anti-Fouling Paints are Toxic," Marine Pollution Bulletin, 49(5-6), 456-464.

Kilbourne, William, Pierre McDonagh, and Andrea Prothero (1997), "Sustainable Consumption and the Quality of Life, A Macromarketing Challenge to the Dominant Social Paradigm," Journal of Macromarketing, 17(1), 4-24. 
Kilbourne, William, (2004), “Globalization and Development: An Expanded Macromarketing View," Journal of Macromarketing, 24(2), 122-135.

Kozinets, Robert V. and Jay M. Handelman (2004), “Adversaries of Consumption, Consumer Movements, Activism, and Ideology," Journal of Consumer Research, 31(3), 691-70.

Krång, Anna-Sara and Mia Dahlström (2006), "Effects of a Candidate Antifouling Compound (Medetomidine) on Pheromone Induced Mate Search in the Amphipod Corophium Volutator," Marine Pollution Bulletin, 52(12), 1776-1783.

Lastovicka, John. L. and Karen V. Fernandez (2005), “Three Paths to Disposition, The Movement of Meaningful Possessions to Strangers," Journal of Consumer Research, $31(4), 813-823$.

Lewis, Alan G. and W. R. Cave (1982), The Biological Importance of Copper in Oceans and Estuaries, Aberdeen: Aberdeen University Press.

Magaudda, Paolo (2011), “When Materiality ‘Bites Back', Digital Music Consumption Practices in the Age of Dematerialization," Journal of Consumer Culture, 11(1), 15-36.

Martin, Diane M. and John W. Schouten (2012) Sustainable Marketing, New Jersey: Pearson Prentice Hall.

McDonagh, Pierre and Andrea Prothero (2014), "Sustainability Marketing Research, Past, Present and Future," Journal of Marketing Management, 30(11-12), 1186-1219.

Mitchell, Robert W., Ben Wooliscroft, and James Higham (2010), "Sustainable Market Orientation: A New Approach to Managing Marketing Strategy," Journal of Macromarketing 30(2), 160-170.

Moisander, Johanna (2007), “Motivational Complexity of Green Consumerism,” International Journal of Consumer Studies, 31(4), 404-409. 
Moisander, Johanna, Anu Valtonen, and Heidi Hirsto (2009), "Personal Interviews in Cultural Consumer Research-Post-Structuralist Challenges," Consumption, Markets and Culture, 12(4), 329-348.

Närvänen, Elina, Nina Mesiranta, and Annilotta Hukkanen (2013), "From Waste to Delicacy, Collective Innovation in Food Disposition Practices Through Bloggin,” In NA Advances in Consumer Research 41, Simona Botti and Aparna Labroo, eds., 316-320.

Nason, Robert W. (2006), “The Macromarketing Mosaic,” Journal of Macromarketing, 26(2), 219-223.

Nicolini, Davide (2017a), "Practice Theory as a Package of Theory, Method and Vocabulary, Affordances and Limitations," in Methodological Reflections on Practice Oriented Theories, Michael Jonas, Beate Littig and Angela Wroblewski eds. New York: Springer, $19-34$

Nicolini, Davide (2017b), "Is Small the Only Beautiful? Making Sense of 'Large Phenomena' From a Practice-Based Perspective," in The Nexus of Practices Allison Hui, Theodore Schatzki and Elizabeth Shove, eds. London: Routledge, 98-113.

NPR (2018), “Audi CEO Arrested in Connection with Volkswagen Emissions Scandal,”( accessed June 22, 2018), [available at https://www.npr.org/2018/06/18/620953719/audiceo-arrested-in-connection-with-volkswagen-emissions-scandal].

Orlikowski, Wanda J. (2007), "Sociomaterial Practices, Exploring Technology at Work," Organization Studies, 28(09), 1435-1448.

Ozdamar-Ertekin, Zeynep and Deniz Atik, (2015), "Sustainable Markets: Motivating Factors, Barriers, and Remedies for Mobilization of Slow Fashion," Journal of Macromarketing 35(1) 53-69. 
Preda, Alex (1999), “The Turn to Things, Arguments for a Sociological Theory of Things," The Sociological Quarterly, 40(2), 347-366.

Price, Linda L., Eric J. Arnould, and Carolyn Folkman Curasi (2000), “Older Consumers’ Disposition of Special Possessions," Journal of Consumer Research, 27(2), 179-201.

Prothero, Andrea, Susan Dobscha, James Freund, William. E. Kilbourne, Michael G. Luchs, Lucie K. Ozanne, and John Thøgersen (2011) “Sustainable Consumption, Opportunities for Consumer Research and Public Policy," Journal of Public Policy and Marketing, 30 (1), 31-38.

Reckwitz, Andreas (2017), "Practices and Their Affects," in The Nexus of Practices Allison Hui, Theodore Schatzki and Elizabeth Shove, eds. London: Routledge, 114-125.

Rios, Lorena M., Patrick R. Jones, Charles Moore, and Urja V. Narayan, (2010), “Quantitation of Persistent Organic Pollutants Adsorbed on Plastic Debris From the Northern Pacific Gyre's “Eastern Garbage Patch,” Journal of Environmental Monitoring, 12(12), 22262236.

Røpke, Inge (2009), “Theories of practice — New inspiration for ecological economic studies on consumption," Ecological Economics, 68(10), 2490-2497.

Sahakian, Marlyne (2010), "Combining Life Cycle Thinking with Social Theory, Case Study of Compact Fluorescent Lamps (CFL) In The Philippines," Sustainability, 2(7), 2349-2364.

Sahakian, Marlyne and Harold Wilhite (2013), "Making Practice Theory Practicable, Towards More Sustainable Forms of Consumption," Journal of Consumer Culture, 14(1), 25-44.

Samuel, Anthony and Ken Peattie (2016), "Grounded Theory as a Macromarketing Methodology: Critical Insights From Researching the Marketing Dynamics of Fairtrade Towns," Journal of Macromarketing, 36(1), 11-26. 
Sassatelli, Roberta (2006), "Virtue, Responsibility and Consumer Choice, Framing Critical Consumerism," In Consuming Cultures, Global Perspectives, Historical Trajectories and Multicultural Conflicts, John Brewer and Frank Trentmann, eds. Oxford: Berg, 219-250. Sassatelli, Roberta (2008), "Representing Consumers, Contesting Claims and Agendas," In The Politics and Pleasures of Consuming Differently, Better than Shopping, Kate Soper, and Martin Ryle and Lyn Thomas, eds. Oxford: Berg, 25-42.

Seaboost (2017), accessed June 22, 2018 [available at (http://www.seaboost.fi/products/seaboostpowerturf/?lang=en)].

Schaefer, Anja and Andrew Crane (2005), “Addressing Sustainability and Consumption,” Journal of Macromarketing, 25(1), 76-92.

Schatzki, Theodore R. (2001), "Practice Minded Orders," in, The Practice Turn in Contemporary Theory, Theodore R. Schatzki, Karin Knorr Cetina and Eike E. von Savigny, eds. London: Routledge, 50-63.

Schatzki, Theodore R. (2002), The Site of The Social, A Philosophical Account of the Constitution of Social Life and Change, University Park, PA:Pennsylvania State University Press.

Scrubbis (2017), accessed June 22, 2018 [available at (http://scrubbis.se/en/)].

Shove, Elizabeth (2010a), "Social Theory and Climate Change, Questions Often, Sometimes and Not Yet Asked," Theory, Culture and Society, 27 (2-3), 277-288.

Shove, Elizabeth (2010b), "Beyond the ABC, Climate Change Policy and Theories of Social Change," Environment and Planning A, 42 (6), 1273-1285.

Shove, Elizabeth (2017), "Matters of Practice," in The Nexus of Practices, Allison Hui, Theodore Schatzki and Elizabeth Shove, eds. London: Routledge, 155-168. 
Shove, Elizabeth, Mika Pantzar, and Matt Watson (2012), The Dynamics of Social Practice, Everyday Life and How It Changes, London: Sage.

Shrivastava, Paul (1995), "The Role of Corporations in Achieving Ecological Sustainability," Academy of Management Review, 20(4), 936-960.

Simkins, Travis J. and Mark Peterson (2016), “Assessing the Value of a Societal-Level Sustainability Index for Macromarketing Research,” Journal of Macromarketing, 36(1), $78-95$

Southerton, Dale and Luke Yates (2015), "Exploring Food Waste Through the Lens of Social Practice Theories: Some Reflections on Eating as a Compound Practice," in Waste Management and Sustainable Consumption: Reflections on Consumer Waste, Karin M.

Esktröm ed. London: Routledge, 133-149.

Spaargaren, Gert (2003), "Sustainable Consumption, A Theoretical and Environmental Policy," Society and Natural Resources, 16(8), 687-701.

Spiggle, Susan (1994), “Analysis and Interpretation of Qualitative Data in Consumer Research, “ Journal of Consumer Research, 21(3), 491-503.

Thøgersen, John J. (2005), “How May Consumer Policy Empower Consumers for Sustainable Lifestyles?," Journal of Consumer Policy, 28(2), 143-177.

Thøgersen, John J. (2010), “Country Differences in Sustainable Consumption: The Case of Organic Food," Journal of Macromarketing, 30(2), 171-185.

Thomas, Kevin V. and Steven Brooks (2010), “The Environmental Fate and Effects of Antifouling Paint Biocides," Biofouling, The Journal of Bioadhesion and Biofilm Research, 26(1), 73-88. 
Van Dam, Ynte K., and Paul AC Apeldoorn (1996), “Sustainable Marketing,” Journal of Macromarketing, 16(2), 45-56.

Varey, Richard J. (2010), “Marketing Means and Ends for a Sustainable Society: A Welfare Agenda for Transformative Change," Journal of Macromarketing, 30(2), 112-126.

Vermeir, Iris and Wim Verbeke (2006), "Sustainable Food Consumption, Exploring the Consumer 'Attitude - Behavioral Intention' Gap,” Journal of Agricultural and Environmental Ethics, 19(2), 169-194.

Warde, Alan. (2005), “Consumption and Theories of Practice,” Journal of Consumer Culture, 5 (2), 131-153.

Warde, Alan (2014), “After Taste, Culture, Consumption and Theories of Practice Introduction, Consumption and The Role of Theory," Journal of Consumer Culture, 14(3), 279-303.

Webster, Frederick E. (1975), "Determining the Characteristics of the Socially Conscious Consumer," Journal of Consumer Research, 2(3), 188-196.

Welch, Dan (2017), “Consumption and Teleoaffective Formations, Consumer Culture and Commercial Communications," Journal of Consumer Culture, 1469540517729008

Welch, Dan and Alan Warde (2017), "How Should We Understand 'General Understandings'?," in The Nexus of Practices, Allison Hui, Theodore Schatzki and Elizabeth Shove, eds. London: Routledge, 183-196.

Welch, Dan and Alan Warde (2015), “Theories of Practice and Sustainable Consumption,” in Handbook of Research on Sustainable Consumption, Lucia A. Reisch and John Thøgersen, eds. Cheltenham: Edward Elgar, 84-100. 
World Commission on Environment and Development (1987), "Report of the World Commission on Environment and Development: Our Common Future," (accessed Oct 12, 2017)[available at http,//www.un-documents.net/wced-ocf.htm].

Young, William, Kumju Hwang, Seonaidh McDonald, and Caroline J. Oates (2010), "Sustainable Consumption, Green Consumer Behaviour When Purchasing Products," Sustainable Development, 18(1), 20-31.

Yngfalk, Carl (2016), “Bio-politicizing Consumption, Neo-Liberal Consumerism and Disembodiment in the Food Marketplace," Consumption Markets \& Culture, 19(3), 275295.

Ytreberg, Erik, Jenny Karlsson, and Britta Eklund (2010), "Comparison of Toxicity and Release Rates of $\mathrm{Cu}$ and $\mathrm{Zn}$ From Anti-Fouling Paints Leached in Natural and Artificial Brackish Seawater," Science of the Total Environment, 408(12), 2459-2466. 